\title{
Dysregulation of follicle development in a mouse model of premature ovarian insufficiency
}

\author{
P Grasa ${ }^{1, *}$, S Sheikh,*, N Krzys ${ }^{1,2}$, K Millar $^{1}$, S Janjua ${ }^{1,2}$, P Nawaggi ${ }^{1}$ and S A Williams ${ }^{1}$ \\ ${ }^{1}$ Nuffield Department of Obstetrics and Gynaecology, University of Oxford, Women's Centre, Level 3, John Radcliffe \\ Hospital, Oxford, UK and 'Department of Physiology, Anatomy and Genetics, University of Oxford, Oxford, UK
}

Correspondence should be addressed to S A Williams; Email: suzannah.williams@obs-gyn.ox.ac.uk

*(P Grasa and S Sheikh are regarded as joint first authors and they contributed equally to this work)

\begin{abstract}
Premature ovarian insufficiency (POI) occurs in $1 \%$ of reproductive-age women. The ovarian manifestation ranges from the presence of a variable population of follicles (follicular) to the absence of follicles (afollicular), and in the majority of cases the cause is unknown. A transgenic mouse model of follicular POI, the Double Mutant (DM), arises from oocyte-specific deletion of Mgat1 and $C 1$ galt1 required for the generation of $O$ - and $N$-glycans. DM females are subfertile at 6 weeks, infertile by 9 weeks and exhibit POI by 12 weeks of age. In this study we investigate the cause of the reduced fertility at 6 weeks and infertility at 9 weeks of DM females.

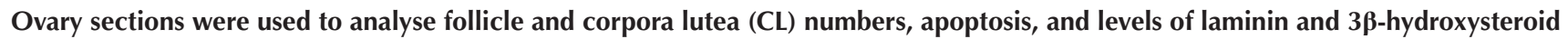
dehydrogenase using immunohistochemistry. After POI, DM females unexpectedly remained sexually receptive. At both 6 and 9 weeks, DM ovaries contained more primary follicles, however, at 9 weeks DM follicles were proportionally healthier, revealed by TUNEL analysis compared with Controls. In 9 week DM ovaries (collected post-mating), secondary follicles had theca and basal lamina structure abnormalities, whilst preovulatory follicles failed to ovulate resulting in the presence of numerous luteinised unruptured follicles, indicative of ovulation failure. Finally, DM ovaries contained more regressing CL with decreased luteal cell apoptosis indicative of a defect in CL regression. Identifying these follicular modifications have provided insight into the aetiology of a model of POI and highlight targets to investigate with the hope of developing new fertility treatments.

Reproduction (2016) 152 591-601
\end{abstract}

\section{Introduction}

Follicle development starts with the activation and development of quiescent primordial follicles that develop through primary, secondary, preantral and antral follicle stages before they ovulate a fertilisable oocyte, however, many follicles undergo atresia and die (Greenwald 1972, Hirshfield 1991). At the primary follicle stage, the oocyte and its supporting cuboidal granulosa cells (GCs) are encapsulated by a basal lamina (BL) composed of extracellular matrix (ECM). The $B L$ maintains the integrity of the follicle and influences follicle growth by regulating the molecules that enter the follicle (Rodgers et al. 1999, Irving-Rodgers et al. 2010). At the secondary follicle stage, theca cells are recruited from the surrounding stromal tissue (Young \& McNeilly 2010) and the GCs proliferate, resulting in the formation of a preantral follicle. This preantral follicle develops an antrum to become an antral follicle, which develops further to become a large preovulatory follicle from which the mature oocyte will ovulate. Complex interactions between the oocyte, the granulosa and theca cells orchestrate follicle development with oocytespecific proteins and glycoproteins playing an active role through their interaction with the surrounding granulosa and cumulus cells (Eppig 2001, Matzuk et al. 2002, Williams \& Stanley 2011, Christensen et al. 2015, Grasa et al. 2015, Ploutarchou et al. 2015). After ovulation, the follicular cells differentiate to form a highly vascularised endocrine organ, the corpus luteum (CL), whose primary function is to produce progesterone to support the ensuing pregnancy. If, however, pregnancy does not occur, the CL regresses (Nelson et al. 1982, Carambula et al. 2002, Davis \& Rueda 2002).

Abnormal control of primordial follicle activation or development can lead to conditions such as premature ovarian insufficiency (POI), previously known as premature ovarian failure, which affects $1-3 \%$ of women under 40 years of age and is idiopathic in over $70 \%$ of cases (Coulam et al. 1986, Meskhi \& Seif 2006, Shelling 2010). There are two main aetiological mechanisms, which give rise to a heterogeneous spectrum of ovarian manifestations. The first is follicle depletion resulting in ovaries devoid of follicles (afollicular POI) and the second mechanism is follicle dysfunction, resulting in a spectrum of follicle development, from the presence of a variable population of follicles, including antral follicles, 
that fail to develop or the presence of only primordial follicles (follicular POI) (Nelson et al. 1994, Meskhi \& Seif 2006, Nelson 2009, Hubayter et al. 2010, Suzuki et al. 2015). Follicular POI accounts for around $50 \%$ of cases (Mehta et al. 1992, Nelson et al. 1994, Massin et al. 2004, Suzuki et al. 2015). Although several factors have been related with $\mathrm{POI}$, in the majority of cases the causal mechanism remains unclear, and further research using POI models is therefore warranted.

A mouse model of follicular POI has been established (Williams \& Stanley 2011); known as the Double Mutant (DM). The genetic origin of the DM mouse is oocyte-specific deletion of two glycosyltransferase genes, C1galt1 (also known as T-syn) and Mgat1, that respectively encode $\beta 1,3$-galactosyltransferase (T-synthase) and $\mathrm{N}$-acetylglucosaminyltransferase I (GlcNAcT-1). T-synthase is required for the generation of core 1-derived O-glycans (Ju et al. 2002a,b), whilst GlcNAcT-1 is required for the synthesis of complex and hybrid N-glycans (Schlesinger et al. 1975, Robertson et al. 1978). Oocyte generated $O$ - and $N$-glycans are involved in the regulation of multiple aspects of follicle development and ovarian function such as the formation of the BL and theca cells, and cumulus expansion (Williams \& Stanley 2008, 2009, Grasa et al. 2012, 2015, Christensen et al. 2015, Ploutarchou et al. 2015).

DM female mice are subfertile at 6 weeks, infertile at 9 weeks and undergo POI by 3 months of age (Williams \& Stanley 2011, Grasa et al. 2012). This drop in fertility of DM females is accompanied by a dysregulation of follicle development and an altered endocrine profile at 3 months (Williams \& Stanley 2011). Although DM females have decreased fertility at 6 weeks, they have a normal ovulation rate, however, DM ovaries contain a larger and more heterogeneous population of $\mathrm{CL}$ (Grasa et al. 2012). By 3 months of age, DM ovaries lack developing follicles and abnormal luteinised structures are present (Williams \& Stanley 2011). Therefore, the clearly defined onset of $\mathrm{POI}$ in the DM makes this an excellent model to study the potential aetiology of POI. In this study, we investigate the onset and aetiology of POI in postpubertal DM females, by studying the reproductive phenotype and ovarian function.

\section{Materials and methods}

\section{Mice}

DM mice are homozygous for floxed Mgat1 and C1galt1 alleles and carry a ZP3Cre recombinase transgene (Williams et al. 2007). The floxed alleles are deleted when exposed to Cre recombinase, expression of which is controlled by the promoter of oocyte-specific ZP3, which is expressed only in the developing oocyte from the primary stage of follicle development (Philpott et al. 1987). Experimental females (Mgat ${ }^{\mathrm{F} / \mathrm{F}} \mathrm{C} 1$ galt $1^{\mathrm{FF}}: \mathrm{ZP} 3 \mathrm{Cre}$ ) carry floxed alleles of Mgat1 and C1galt1 and a ZP3Cre recombinase transgene, whilst Control females lack the ZP3Cre transgene (Mgat ${ }^{\mathrm{F} / \mathrm{F}}$ C1galt1 $1^{\mathrm{F} / \mathrm{F}}$ ) (Williams et al. 2007, Williams \& Stanley 2011). The ZP3Cre transgene does not affect fertility (Shi et al. 2004, Williams et al. 2007).

Mice were maintained in individually ventilated cages in 12:12 h light-darkness cycles unless specified otherwise.

\section{Ethical approval}

All experiments using mice were carried out with the approval of the Local Ethical Review Panel at the University of Oxford under licence in accordance with the UK Animals (Scientific Procedures) Act 1986.

\section{Genotyping}

Mice were genotyped using protocols as described previously (Grasa et al. 2012, 2015).

\section{Reproductive parameters and oestrous cycle evaluation}

To assess sexual receptivity, Control and DM females at 6 weeks of age were caged with males and mating assessed daily (confirmed by the presence of a vaginal plug), until 6 months of age. To evaluate the oestrous cycle, vaginal smears were obtained daily between 08:00 and 10:00 from Control and DM females that were caged together in open top cages in close proximity to males from 4 weeks to 6 months of age. Cell smears were stained with Giemsa (Sigma-Aldrich) and assessed to determine the four stages of the oestrous cycle as described previously (Grasa et al. 2015).

\section{Ovarian histology and follicle counts}

To ensure ovaries were collected at the same stage of the oestrous cycle, ovaries were collected on the day after mating from females put together with males at 6 or 9 weeks of age. Ovaries were collected from females that mated within 7 days of joining. Ovaries were weighed, fixed in $10 \%$ buffered formalin (Sigma-Aldrich) for $8 \mathrm{~h}$, paraffin embedded, $5 \mu \mathrm{m}$ sections collected and mounted on glass slides.

To determine follicle numbers, every 10th serial section was stained with haematoxylin (Shandon Gill 2 Hematoxylin; Thermo Fisher Scientific) and eosin (Sigma-Aldrich) (H\&E) for analysis. Sections were visualised using a DM2500 Leica microscope (Microscope Services Ltd, Woodstock, UK) and imaged using a MicroPublisher 5.0 RTV camera (Qimaging, Microscope Services Ltd). Only morphologically healthy follicles with a central oocyte and a visible nucleus were assessed. Follicles were classified as described by Grasa et al. (2015). For analysis, follicles were grouped into four categories: primary ( $3 a$ and $3 b$ ), secondary (type 4), preantral ( $5 \mathrm{a}$ and $5 \mathrm{~b}$ ) and antral (including $5 \mathrm{a}+\mathrm{A}, 5 \mathrm{~b}+\mathrm{A}$ (which develop an early antrum (A)), 6 and 7). The number of luteinised unruptured follicles (LUFs) and CL were also recorded. LUFs are large antral follicles that contain an oocyte and show signs of GC luteinisation, these were only present in postmating ovaries at 9 weeks. To identify and record the number of $C L$ present in the ovaries, CL were followed through serial 
sections (every $50 \mu \mathrm{m}$ ) of the entire ovary, thus avoiding miscounting.

\section{Immunohistochemistry}

Immunohistochemistry (IHC) was performed on $5 \mu \mathrm{m}$ paraffinembedded sections to detect laminin and $3 \beta$-hydroxysteroid dehydrogenase (3BHSD). Sections were dewaxed with xylene and rehydrated using decreasing concentrations of ethanol in $\mathrm{dd}_{2} \mathrm{O}$. Slides were washed in tris buffered saline (TBS: $0.1 \mathrm{M}$ Tris $\mathrm{pH} 7.5$ and $0.3 \mathrm{M} \mathrm{NaCl}$ ) with $0.05 \%$ Tween 20 (TBST). Endogenous peroxidase was quenched using 3\% $\mathrm{H}_{2} \mathrm{O}_{2}$ (Thermo Fisher Scientific) in PBS for $5 \mathrm{~min}$. Non-specific primary antibody binding was blocked using goat serum in TBS (NGS: Vectastain ABC Elite Kit, Vector Laboratories, Peterborough, UK). Primary antibodies were diluted in the blocking solution and incubated overnight at $4{ }^{\circ} \mathrm{C}$. The rabbit anti-laminin (L9393; Sigma) was used at 1:500 and anti3BHSD (generously donated by Prof. Ian Mason from the University of Edinburgh) was used at 1:2000 dilution; blocking solution was used as a negative control. After three washes with TBST, sections were incubated with biotinylated antirabbit IgG secondary antibody (Vectastain ABC Elite Kit) for $1 \mathrm{~h}$, followed by $\mathrm{ABC}$ solution (Vectastain $\mathrm{ABC}$ Elite Kit) for 30 min. A 3,3'-diaminobenzidine peroxidase substrate kit (Vector Labs) was used to visualise localisation. The slides were counterstained with haematoxylin, dehydrated, mounted with DEPEX (VWR, Leicestershire, UK) and imaged. Follicles were classified as positive or negative for the presence of 3BHSD in GCs, whilst laminin detection was classified as low or high. The number of theca cell layers was counted and the depth of theca layer measured using ImageJ (National Institutes of Health, Bethesda, Maryland, USA).

\section{$C L$ regression evaluation}

To assess $\mathrm{CL}$ regression, ovaries were collected from Control and DM females at 6 weeks of age, fixed, sectioned and stained with $\mathrm{H} \& \mathrm{E}$. The number of $\mathrm{CL}$ present was recorded and the area of each CL was determined in the largest cross section using ImageJ software. CL were classified as Newly Formed, Type I regressing or Type II regressing based on the morphology and cellular type present. Newly formed CL were composed of luteal cells with a small amount of basophilic cytoplasm, and may contain a central fluid-filled cavity. For analysis, regressing CL were classified as Types I and II; Type I regressing CL contained luteal cells with abundant eosinophilic cytoplasm, distinct cell borders and indistinct interstitial cells whilst Type II regressing CL were smaller with a more conspicuous interstitium.

\section{TUNEL assay}

Apoptosis of $\mathrm{CL}$ was assessed in formalin fixed ovarian sections from 6 week Control and DM females using the TUNEL assay (ApopTag kit; Merck Millipore, Watford, Hertfordshire, UK) as described by Grasa et al. (2015). Only follicles sectioned through the oocyte were analysed and assessed as being either healthy, containing low or high levels of apoptosis, or dead.
Healthy follicles had no apoptotic cells and a healthy oocyte. Follicles classified with low levels of apoptosis had some apoptotic cells and a healthy oocyte. Follicles classified with high levels of apoptosis had numerous apoptotic cells but an intact follicle structure. Dead or dying follicles had lost their follicular and/or oocyte structure, large amounts of apoptosis in GCs and oocyte blebbing. To quantify the level of apoptosis in $C L$, mean pixel intensity of TUNEL staining of luteal cells of Type I and II regressing CL was determined using ImageJ.

\section{Statistical analyses}

Statistical analysis was carried out using GraphPad Prism software (GraphPad Software, version 4.0b, 2004). D'AgostinoPearson normality test or Shapiro-Wilk normality test was applied to test Gaussian (normal) distribution of the samples. The Mann-Whitney $U$ test was performed to detect differences between groups with non-parametrical distribution and equal variances. Unpaired $T$ test was used to analyse samples with normal distribution. A one-way ANOVA followed by multiple comparison tests were used to analyse the mean number of follicles per ovary. Results are presented as mean \pm S.D./S.E.M. $P \leq 0.05$ was considered significant.

\section{Results}

\section{DM females show normal oestrous cycles and sexual receptivity}

Since DM females have a normal ovulation rate but decreased fertility at 6 weeks of age, which declines dramatically by 9 weeks of age, and are infertile by 3 months of age (Williams et al. 2007, Williams \& Stanley 2011, Grasa et al. 2012), we investigated the aetiology of POI. The time to first mating (Control $4.8 \pm 1.1$ days $n=4$, DM $2.3 \pm 0.8$ days $n=4$ ) or first litter (Control $27.6 \pm 2.5$ days $n=5$, DM $24.0 \pm 1.0$ days $n=4)$ did not differ between Control and DM females consistent with our previous studies of this model (Williams \& Stanley 2011, Grasa et al. 2012). The age at first oestrous (i.e. puberty), as detected by the presence of cornified cells, also did not differ between Control (35.0 \pm 1.3 days, $n=9)$ and DM (35.3 \pm 1.6 days, $n=8)$ females.

Oestrous cycle parameters were evaluated between 6 and 8 weeks of age, when DM females are fertile and ovulate, and 4-5 months of age, after POI has occurred and they are infertile. There were no differences in oestrous cycle length between Control and DM females at either of the time points (Fig. 1A and B). Although DM females did not have any litters after the first litter at 9 weeks of age they remained sexually receptive as all DM females mated frequently throughout the study period; however, the period between the plugs could be divided into three separate groups (Fig. 1C). The first interplug period was $\sim 4$ days consistent with a normal oestrous cycle (Fig. 1C, black triangles), the second was an interplug interval of 8-14 days which is consistent with pseudopregnancy (Fig. 1C, open diamonds) and the third, was a longer 

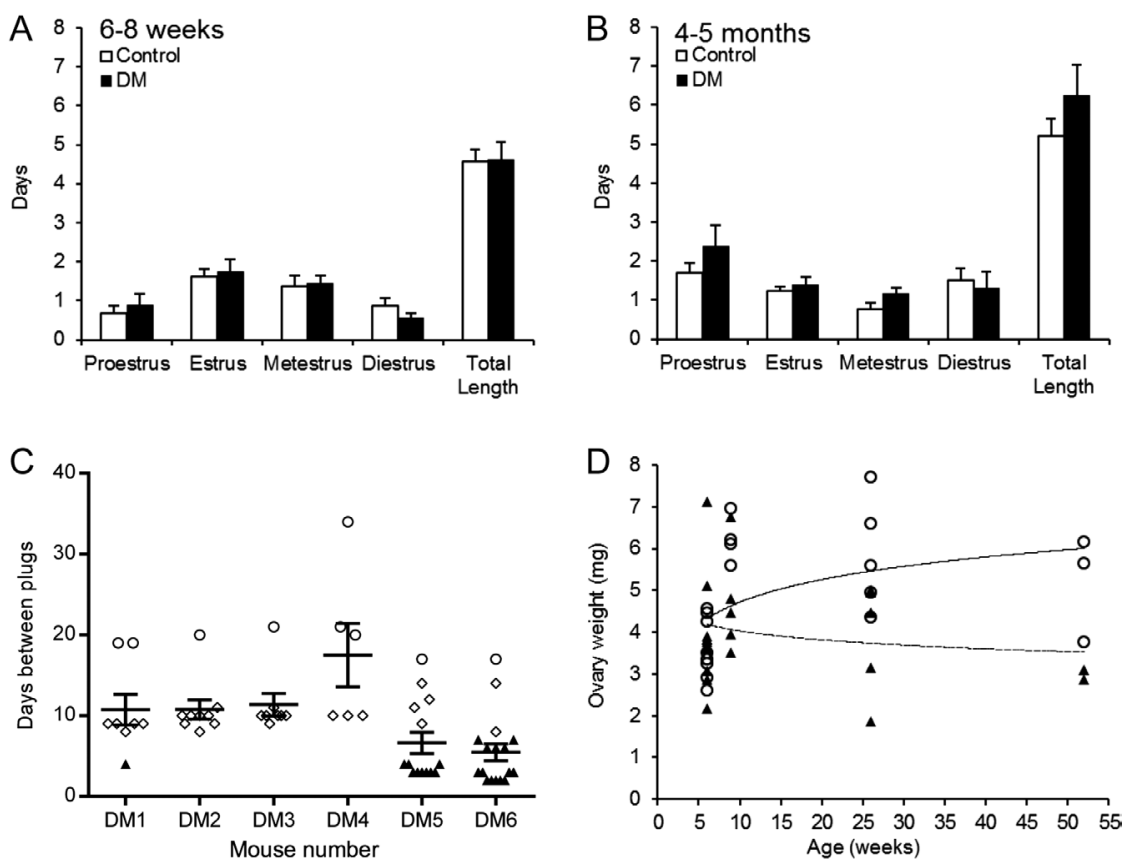

Figure 1 Reproductive parameters. (A and B) Oestrous cycle length. The oestrous cycle was evaluated in Control and DM females at (A) 6-8 weeks and (B) 4-5 months of age by cytological analysis of vaginal washes. (C) Interval between mating plugs of DM females. DM females were caged with males and mating plugs were checked daily from 4 weeks to 6 months of age. Control littermates had a litter every 3 weeks and therefore, are not shown here. All DM females mated repeatedly throughout the study period. Half of the DM females had plug intervals of $\sim 4$ days (black triangle; consistent with the duration of the oestrous cycle), all DM females had interplug periods of 8-14 days indicative of pseudopregnancy (open diamonds), and all exhibited interplug intervals of 17-34 days (open circles) where they appeared pregnant but did not litter down (resorption of small litters occurs in mice). (A-C) Results are expressed as mean \pm S.E.M. (D) Average ovary weight of Control (open circles) and DM (black triangles) females from 6 weeks to 1 year of age. Trend line of Control (solid line) and DM (broken line) ovary weight. interplug interval of 17-34 days (Fig. 1C, open circles) where females often appeared pregnant but never gave birth; we hypothesise that these females became pregnant with small litters which were resorbed.

The weight of DM and Control ovaries from mice from 6 weeks to 1 year of age were compared. An agedependent decrease in DM ovary weight was observed whereas ovary weight increased with age in Controls (Fig. 1D).

\section{Follicular development in DM postpubertal females is altered}

As reported previously, there is a dramatic decrease in the number of developing follicles in ovaries of 3-month-old DM females compared with 3-week DM or Control females (Williams \& Stanley 2011). To investigate the decline in follicle numbers and thus the onset of ovarian failure, follicle development was evaluated (in ovaries collected after mating to ensure cycle synchronisation) at two time points, when females were subfertile at $\sim 6$ weeks (Control $6.5 \pm 0.1$ weeks; $n=3$, DM $6.4 \pm 0.1$ weeks; $n=3$ ) and infertile at $\sim 9$ weeks (Control 9.4 \pm 0.0 weeks; $n=3$, DM 9.4 \pm 0.1 weeks; $n=3$ ) (Fig. 2) (hereafter referred to as 6 weeks and 9 weeks). Control and DM ovaries at both 6 and 9 weeks contained many follicles whilst DM ovaries at 9 weeks also contained abnormal large antral follicles with oocytes missing a ZP and a thickened granulosa layer (Fig. 2A). At both 6 and 9 weeks of age, there were significantly more primary follicles in the DM ovaries when compared with Controls (Fig. 2B). Further breakdown of follicle stages into subgroups revealed that DM ovaries contained more 3a follicles with an increase of $116 \%$ at 6 weeks and $140 \%$ at 9 weeks (Fig. 2C), which is consistent with the previously reported findings at 3 months (Williams \& Stanley 2011).

\section{DM ovaries at 9 weeks contain a higher proportion of healthier follicles}

Apoptosis in follicles from 6 and 9 week ovaries was evaluated by TUNEL analysis. Follicles were classified as healthy, with low or high levels of apoptosis, or dying/ dead (Fig. 2D). At 6 weeks of age there was no difference in the proportion of follicles in each of these categories between Controls and DM, however, at 9 weeks of age, of the few follicles that were present in DM ovaries, a higher proportion of these follicles were healthier compared with Controls ( $P \leq 0.05)$ (Fig. 2E).

\section{DM follicles have a modified $B L$, a decreased number and depth of theca cell layers, accompanied by increased laminin content}

Next, we analysed the structure of the surviving follicles at 9 weeks of age, to determine if these were morphologically normal. First, integrity of the $\mathrm{BL}$ was assessed and follicles were classified as $\leq 50 \%$ defined, where the BL was too thin to identify or was indistinguishable from the surrounding stroma, or $>50$ defined, where the BL was clearly seen surrounding the majority of the follicle (Fig. 3A). DM had a significantly 
A
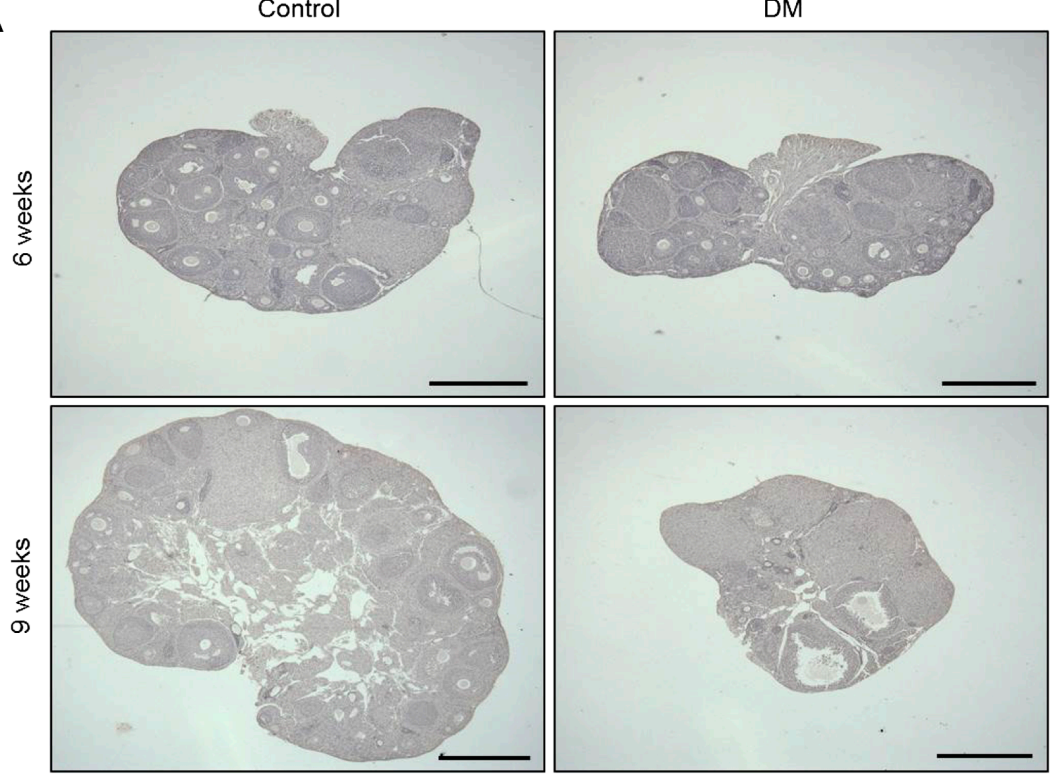

B

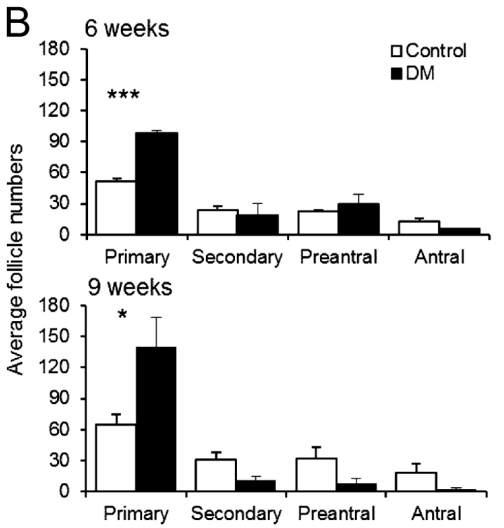

D

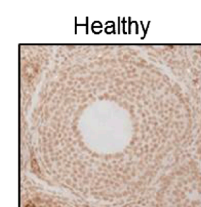

High apoptosis
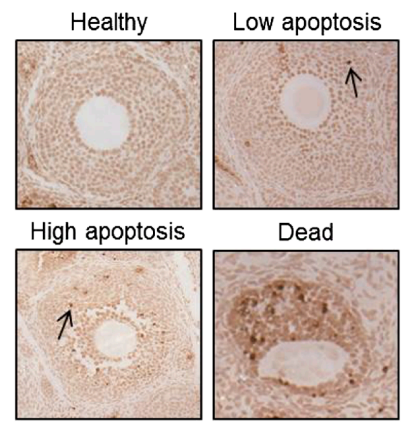

Dead

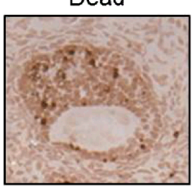

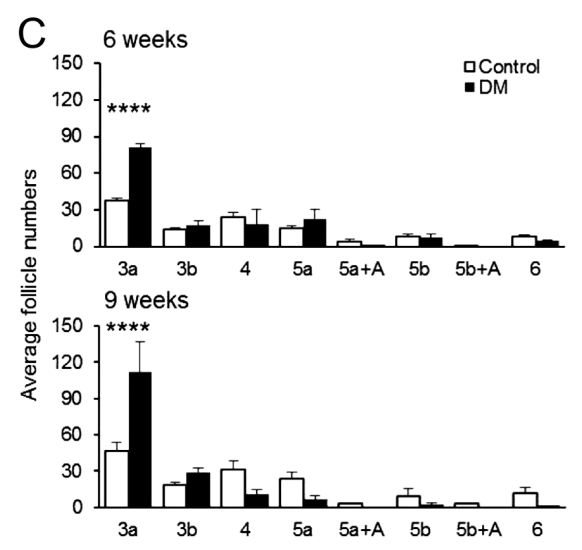

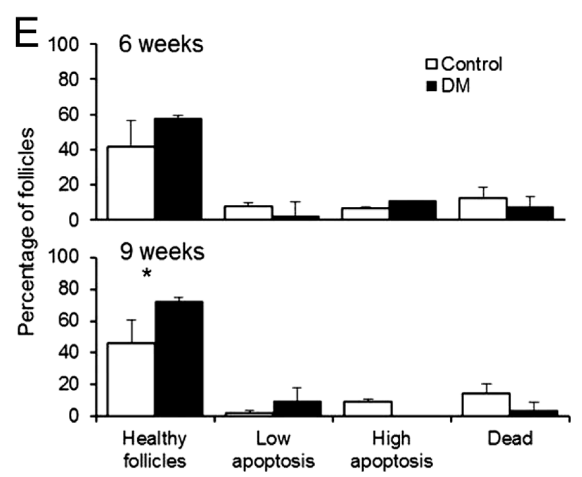

Figure 2 Assessment of follicle development in 6- and 9-week-old mouse ovaries.

(A) Morphology of ovaries collected the day after ovulation at 6 and 9 weeks. Scale bar $500 \mu \mathrm{m}$. (B) Average number of follicles at the primary, secondary, preantral and antral stages of development from 6- to 9-week-old Control ( $n=3$ mice) and DM ( $n=3$ mice) ovaries. (C) Average number of follicles at each discrete stage of development (3a, 3b, 4, $5 a, 5 a+A, 5 b, 5 b+A$ and 6$)$ as per Grasa et al. (2015) from 6 and 9-week-old Control ( $n=3$ mice) and DM ( $n=3$ mice) ovaries collected the day after ovulation. (B-D) Results are expressed as mean \pm S.E.M. (D) Representative images of TUNEL staining scale used to assess levels of apoptosis in follicles. Arrow shows apoptotic cells. (E) Levels of apoptosis detected in follicles at 6 weeks of age and (Controls $n=96$ follicles; $n=3$ mice, DM $n=90$ follicles; $n=3$ mice) 9 weeks of age (Controls $n=116$ follicles; $n=3$ mice, DM $n=34$ follicles; $n=3$ mice).

Results are expressed as mean \pm S.D. $* P \leq 0.05$, $* * * P \leq 0.001, * * * * P \leq 0.0001$. higher proportion of follicles with $\leq 50 \%$ defined $\mathrm{BL}$ at stages 4 and 5 a (Control $n=11$ follicles; $n=3$ mice, DM $n=9$ follicles; $n=3$ mice) (Fig. 3B).

As reported previously, DM females have lower levels of testosterone at 3 months (Williams \& Stanley 2011); therefore, we analysed the androgen generating theca cell layer at 9 weeks of age. Analyses revealed that DM follicles have a decreased theca interna depth early in development, when compared with Control follicles (Fig. 3C), which is attributed to a reduced number of theca cell layers compared with Control follicles (Control $n=106$ follicles; $n=3$ mice, DM $n=28$ follicles; $n=3$ mice) (Fig. 3D).

Finally, ECM laminin content within the thecal compartment was analysed by $\mathrm{IHC}$ and categorised as 'high', where intense staining of laminin was detected around the entire BL, or 'low' content, where there was 
A

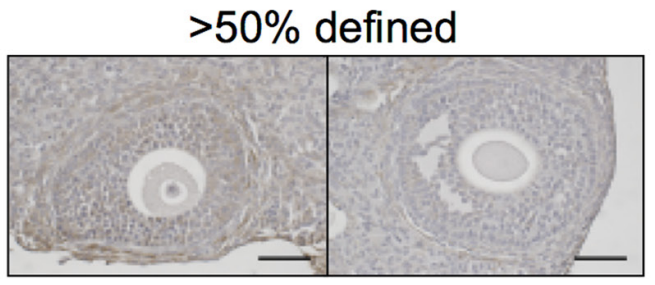

$\leq 50 \%$ defined

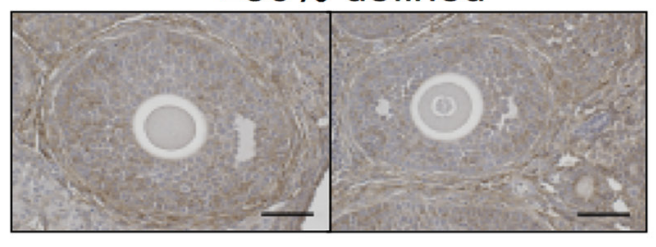

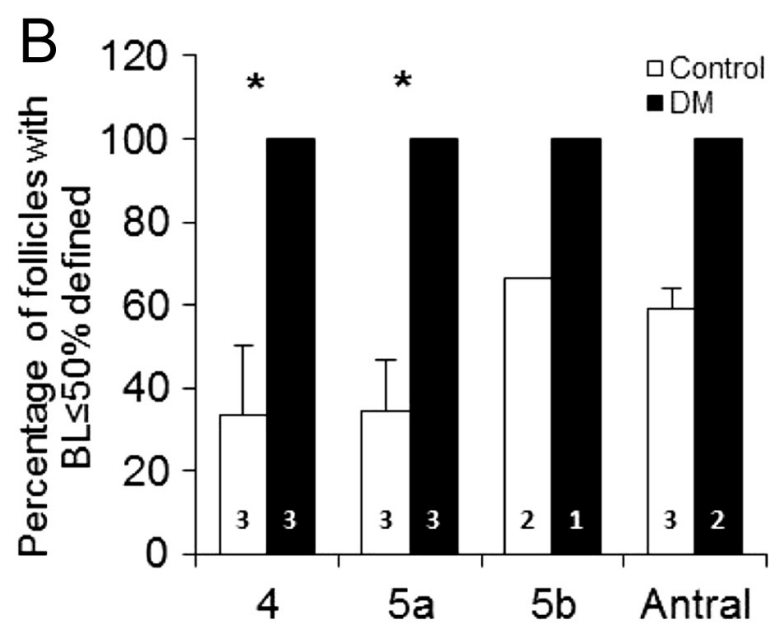
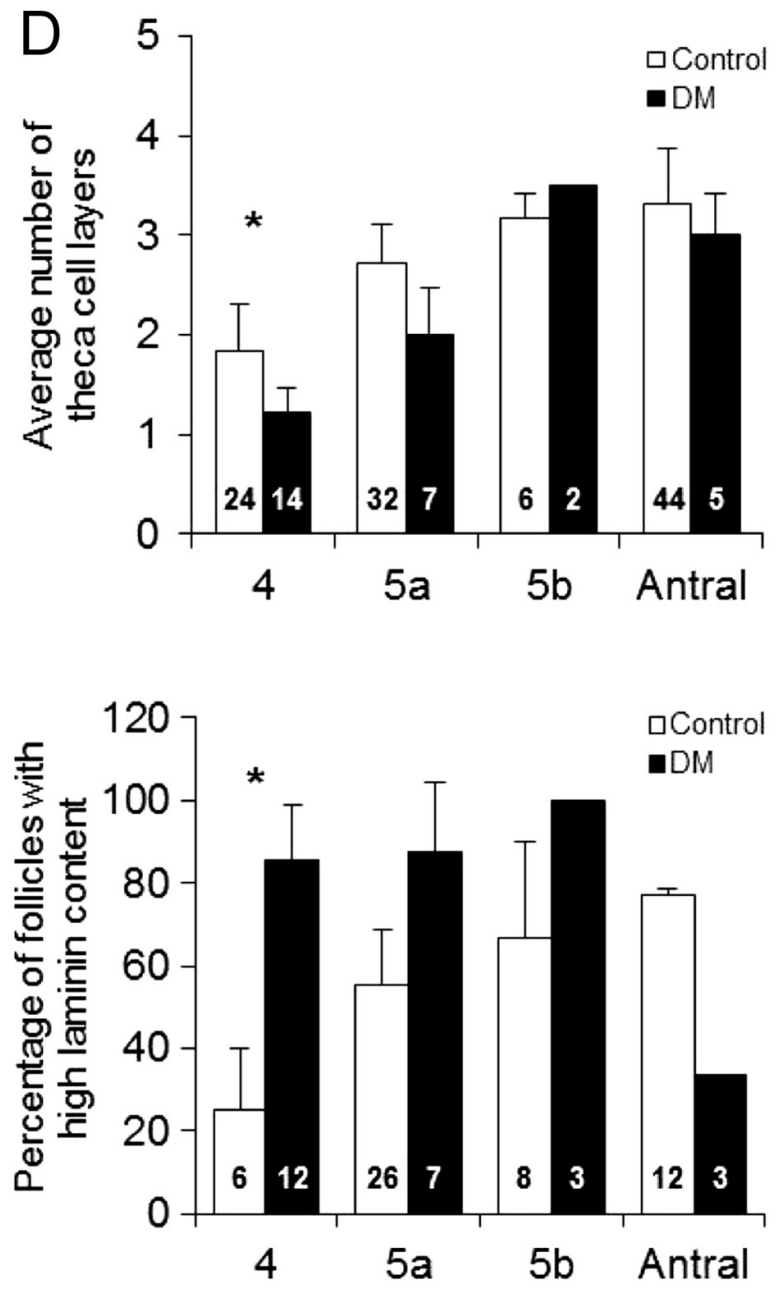

Figure 3 Analysis of basal lamina, theca cells and laminin by immunohistochemistry. (A) Representative images defining how follicle BL was classified as either $\leq 50 \%$ or $>50$ BL defined. (B) Proportion of Control and DM follicles at 9 weeks of age (Control $n=11$ follicles; $n=3$ mice, DM $n=9$ follicles; $n=3$ mice) classified as having less than or equal to $50 \%$ or more than $50 \%$ BL defined. (C and D) The theca cell depth and the number of theca cell layers are both reduced in DM follicles compared with Controls at 9 weeks of age (Control $n=106$ follicles; $n=3$ mice, DM $n=28$ follicles; $n=3$ mice). (E) Laminin detection in ovary sections using IHC revealed that DM follicles at the secondary stage (stage 4 ) have a higher laminin content in the theca compartment than Controls at 9 weeks of age. Results are expressed as mean \pm S.E.M. Numbers in columns represent number of follicles. ${ }^{*} P \leq 0.05$. 

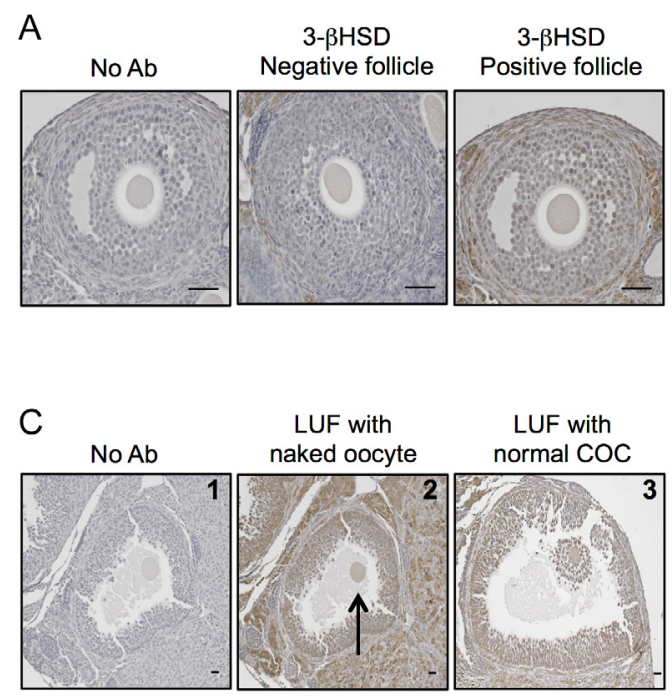

\section{B}
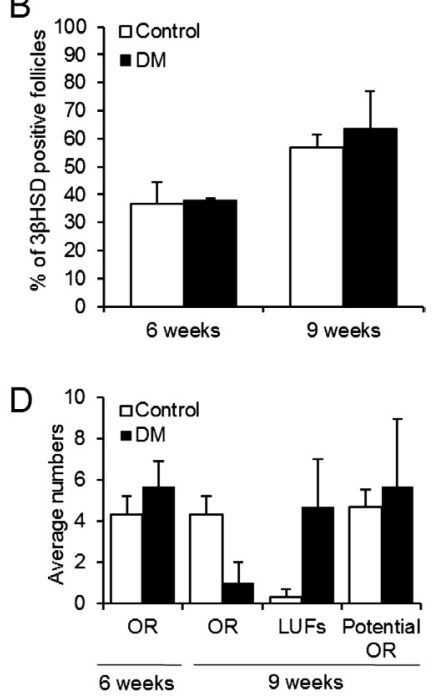

Figure 4 3BHSD detection in Control and DM ovarian follicles using IHC. (A) Follicles not incubated with antibody (No Ab), follicles incubated with 3BHSD antibody and were either negative for 3BHSD (3BHSD negative follicle) or 3BHSD was detected (3BHSD positive follicle) at 6 and 9 weeks of age (scale bars $=50 \mu \mathrm{m}$ ). (B) Proportion of follicles in Control and DM ovaries either positive or negative for 3BHSD detection. (C1-3) LUFs in Control and DM ovaries at 9 weeks of age. Scale bars correspond to $100 \mu \mathrm{m}$. (C1) Follicles not incubated with antibody. (C2) Arrow shows an oocyte free of cumulus cells in a LUF. (C3) A cumulus oocyte complex within a LUF. (D) To assess if LUFs accounted for the previously reported drop in ovulation rate (OR) in DM between 6 and 9 weeks of age, the right ovary OR for Control and DM ovaries at 6 and 9 weeks of age was assessed by number of eggs collected from the right ovary. The OR at 9 weeks was added to the number of LUFs present in the right ovary at 9 weeks to calculate the 'potential OR' (Control $n=3, \mathrm{DM} n=3$ ). Results are expressed as mean \pm S.E.M. faint or no visible staining. The percentage of DM follicles with high laminin content was higher at the secondary stage when compared with Controls and levels did not drop until the antral stage, whereas Control follicles exhibited a gradual increase in laminin content during development (Fig. 3E).

\section{The decrease in ovulation rate in DM ovaries at 9 weeks post-mating is due to premature luteinisation of preovulatory follicles}

To explore the molecular mechanisms underlying the altered follicle development, changes in the levels of 3BHSD, a marker of steroidogenic activity, were assessed in ovaries collected after mating using IHC. Developing follicles were assessed and classified as either positive or negative for detection of 3BHSD in the GC compartment (Fig. 4A). Large unruptured preovulatory follicles containing an oocyte with GCs staining strongly positive for 3BHSD were classified as LUFs. No differences were found in the proportions of developing follicles staining positively between DM and Control ovaries at 6 weeks (Control $n=23$ follicles; $n=3$, DM $n=24$ follicles; $n=3$ ) or 9 weeks (Control $n=70$ follicles; $n=3$, DM $n=15$ follicles; $n=3$ ) (Fig. 4B). However, LUFs were detected at 9 weeks of age in both Control and DM ovaries (Fig. 4C). The oocytes of some DM LUFs lacked cumulus cells (Fig. 4C2). The number of LUFs in Control ovaries was very low, with less than one found on average; however, in DM ovaries, $>4$ on average were present (Fig. 4D).

To ascertain if DM females have a decreased ovulation rate, and thus fertility, at 9 weeks of age due to the premature luteinisation of preovulatory follicles, we examined the ovulation rate of the right ovary (determined by the number of eggs collected from the right oviduct) and the numbers of LUFs present in the right ovary (counted by histological analysis). Consistent with previous findings (Grasa et al. 2012), the ovulation rate at 6 weeks did not differ between DM $(5.67 \pm 2.08$; $n=3$ ) and Controls (4.33 $\pm 1.53 ; n=3$ ) (Fig. 4D); overall average ovulation rate per mouse did not differ between Controls and DM (both ovaries: DM $8.00 \pm 3.00 ; n=3$ Control $8.33 \pm 0.58 ; n=3$ ). Whereas at 9 weeks of age, although the right ovary ovulation rate for Controls at 9 weeks of age $(4.33 \pm 1.53)$ was consistent with right ovary ovulation rate for Controls at 6 weeks of age $(4.33 \pm 1.53)$, the DM right ovary ovulation rate had declined dramatically $(1.00 \pm 1.73) \quad(P=0.07)$ (both ovaries: DM 1.0 $\pm 1.73 ; n=3$ Control $9.00 \pm 2.65 ; n=3$ ). For both Control and DM females, the ovulation rate at 9 weeks of age (assessed by number of eggs collected from the right oviduct) and the number of LUFs present in the right ovary at 9 weeks of age were combined to calculate the 'potential ovulation rate' (Fig. 4C). The 'potential ovulation rate' calculated for DM at 9 weeks of age matched that of Control and DM females at 6 weeks of age suggesting the decrease in ovulation rate at 9 weeks of age may be due to premature luteinisation of preovulatory follicles.

\section{DM ovaries contain more but smaller regressing $C L$ than Control ovaries}

Previous results have shown that despite DM females ovulating equivalent numbers of eggs to Controls at 


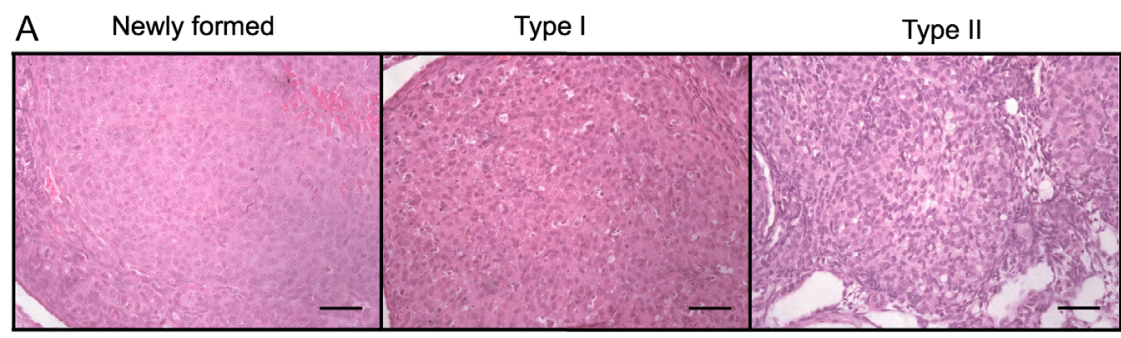

B
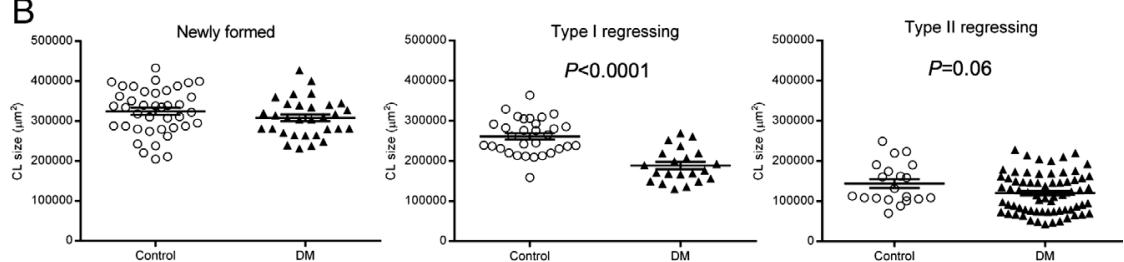

C

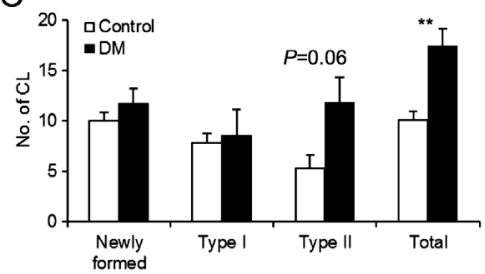

6 weeks of age, ovaries contain a higher number of $\mathrm{CL}$, albeit different in size and appearance (Grasa et al. 2012). In this study, we evaluated if the increased number of $\mathrm{CL}$ in 6-week DM ovaries is due to defects in CL regression. The $\mathrm{CL}$ present in the ovaries were counted and morphologically classified as Newly formed CL, coming from the last ovulation or Type I or Type II regressing CL (Control $n=9$, DM $n=8$ ) (Fig. 5A). The size of Newly formed $\mathrm{CL}$ in $\mathrm{DM}$ was similar to Control CL (Fig. $5 \mathrm{~B}$ ).
Figure 5 Assessment of $C L$ regression in Control and DM ovaries at 6 weeks of age. (A) Representative images of Newly formed, Type I and II regressing CL. Scale bars correspond to $50 \mu \mathrm{m}$. (B) CL size of Newly formed, Type I and II regressing CL in Control (open circles) and DM (black triangles) ovaries measured in the central CL cross section. DM have smaller Type I and II regressing CL compared with Controls (Newly Formed: Control $n=40$ and DM $n=31$, Type I regressing: Control $n=31$ and DM $n=21$, Type II regressing: Control $n=20$ and DM $n=69$ ). Individual points represent data for each CL and the error bar is mean \pm S.E.M. (C) Number of each type of $\mathrm{CL}$ present in Control and DM ovaries. NB Each female did not contain all three types of CL. Newly formed (Control $n=4$, DM $n=3$ ), Type I (Control $n=4, \mathrm{DM} n=3$ ) and II (Control $n=3$, DM $n=6$ ) regressing and total $\mathrm{CL}$ (Control $n=9$, DM $n=8$ ). Results are expressed as mean \pm S.E.M. ${ }^{* *} P \leq 0.01$.
A
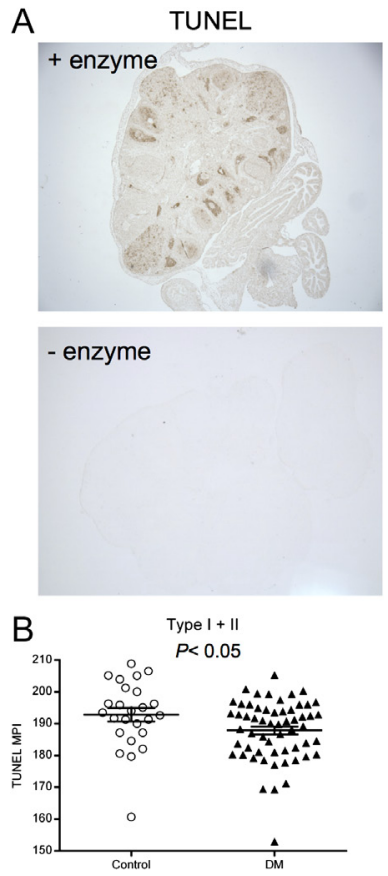

Type I
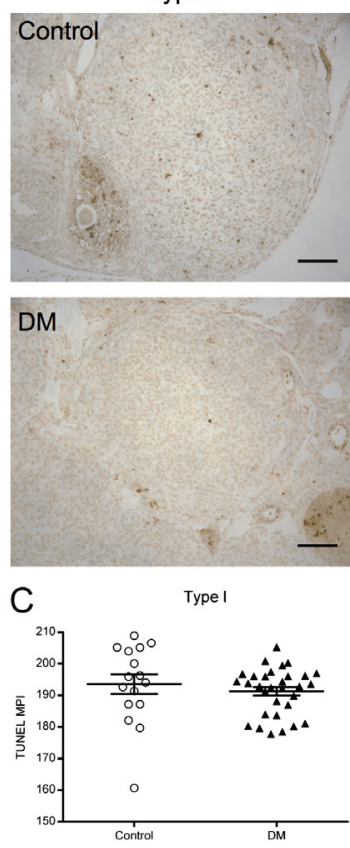
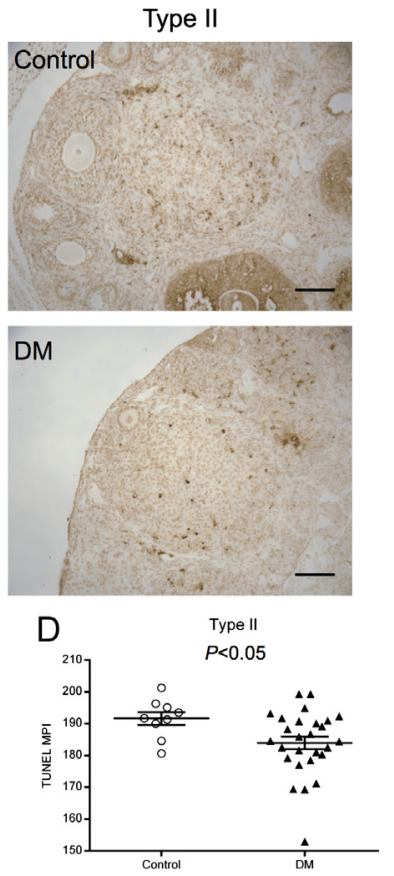

Figure 6 Assessment of apoptotic cells in CL. (A) Representative images of ovary sections subjected to the TUNEL assay with or without the enzyme, and of Type I and Type II CL subjected to the TUNEL assay from Control $(n=3)$ and DM $(n=4)$ ovaries. Scale bars correspond to $50 \mu \mathrm{m}$. (B) Mean pixel intensity (MPI) of TUNEL staining of Type I+ II CL combined, (C) Type I CL (Control $n=16$ and DM $n=31$ ) and (D) Type II CL (Control $n=9$ and DM $n=27$ ). Individual points represent data for each $\mathrm{CL}$ and the error bar is mean \pm S.E.M. 


\section{Apoptosis of DM regressing $C L$ is decreased}

To determine whether the increased number of $\mathrm{CL}$ in DM ovaries is due to aberrant regression, apoptosis of luteal cells from regressing $\mathrm{CL}$ (Types I and II) was evaluated using the TUNEL assay (25 Control regressing $\mathrm{CL}, n=3$ mice and $58 \mathrm{DM}$ regressing $\mathrm{CL}, n=4$ mice) (Fig. 6). There was a decrease in TUNEL staining of all regressing $\mathrm{CL}$ in $\mathrm{DM}$ ovaries compared with Control $\mathrm{CL}$ (Type I+II, $P \leq 0.05$ ) (Fig. 6B). When Types I and II were analysed separately, TUNEL staining was found to be equivalent in Type I Control and DM CL (Fig. 6C) but decreased in Type II DM CL (Fig. 6D). These data reveal a defect in structural regression that would explain the higher number of $\mathrm{CL}$ present in DM ovaries.

\section{Discussion}

Although several factors have been associated with $\mathrm{POI}$, the mechanisms that cause ovarian dysfunction are poorly understood and therefore research is essential with the overarching aim of developing potential treatments. The DM mouse is a model of POI exhibiting a rapid deterioration of ovarian function from a subfertile state at 6 weeks to infertile at 9 weeks with POI by 3 months of age (Williams \& Stanley 2011, Grasa et al. 2012). Therefore, the DM model provides us with the opportunity to investigate how the structure and function of follicles is modified during the onset of $\mathrm{POI}$ and the mechanism(s) involved in the reproductive dysfunction.

Follicle counts at both 6 and 9 weeks of age revealed increased numbers of primary follicles which, can be attributed to either overactivation of primordial follicles or a block in follicle development. As the increase in primary follicle number does not correspond with an increase in the number of developing follicles, this suggests that the disruption of glycans impacts either growth of follicles or their progression to advanced FSHdependent stages.

Whilst ovaries from prepubertal DM mice at 3 weeks of age are grossly normal and contain follicles at all stages of development (Williams \& Stanley 2011), we report here that follicle development in postpubertal ovaries is dysregulated. Recently, it has been identified that two waves of follicle activation exist within the mouse ovary, the first (prepubertal) and second (postpubertal) waves (Hirshfield 1992, Mork et al. 2012, Zheng et al. 2014). A recent study (Zheng et al. 2014) has shown that the first wave of follicles are responsible for the induction of puberty, the establishment of the hypothalamic-gonadal axis and are ovulated, thus contributing to early fertility. These are progressively replaced by follicles from the second wave, which last through the remaining reproductive lifespan. The decline in DM ovarian function is temporally similar to the demise of the first wave of follicle development. Indeed, at 3 months of age, when only the second wave of follicle development exists in the ovary, DM females undergo POI. Therefore, the phenotype of DM females could be due to defects in the postpubertal wave of follicle development; unfortunately, this hypothesis cannot be tested due to genetic incompatibilities between the DM model and the model used to track the two waves.

Ovaries from 9 week DM females contained fewer developing follicles, but of those present, a higher proportion were healthier as assessed by the TUNEL assay compared with Controls. This indicates that follicles that pass the developmental 'block' are more likely to survive, potentially due to decreased competition. Increased follicle survival may also be linked to the increased FSH levels (Williams \& Stanley 2011), which promotes the survival of developing follicles (Dorrington et al. 1983). Oocyte-specific factors are also known to play a role in apoptosis and we have recently shown that ovaries generating oocytes devoid of core $1 \mathrm{O}$-glycans have a higher expression ratio of GDF9:BMP15 accompanied with reduced apoptosis (Williams \& Stanley 2008, Grasa et al. 2015). Furthermore, mutations in GDF-9 and BMP15 have been reported in some women with $\mathrm{POI}$ and are believed to play a role in ovary dysfunction (Dixit et al. 2006, Laissue et al. 2006) and hence we propose the high FSH levels and potential alterations in GDF-9 and $B M P-15$ could be promoting DM follicle survival.

Next, we assessed the structure of the surviving follicles to determine if these were morphologically normal. Secondary DM follicles had a thinner theca cell layer and an indistinct BL. At the secondary follicle stage, theca cells are recruited from the stroma and produce testosterone, which is crucial for the growth and development of the follicles (Young \& McNeilly 2010). Therefore, a reduced theca cell layer at the secondary stage indicates a delay in their recruitment to the follicle. This in turn could affect follicle development and in combination with the decreased number of developing follicles found in DM ovaries could explain the low serum levels of testosterone found at 3 months of age (Williams \& Stanley 2011).

Previously, we have shown that the lack of core 1 O-glycans on oocyte glycoproteins regulate the expression of ECM proteins and also the form and function of the BL (Christensen et al. 2015). Changes in the structure of the $\mathrm{BL}$ and the ECM proteins will likely alter the traffic of regulatory molecules and for the release of the oocyte at ovulation. The ECM protein laminin has been reported to play a role in luteinisation; however, the reports are conflicting. Rat GCs cultured with laminin were stimulated to produce progesterone and exhibited luteinising effects (Aten et al. 1995). However, when human GCs were cultured with laminin, progesterone synthesis was suppressed (Fujiwara et al. 1997). Thus, alterations in laminin levels and structure of the $\mathrm{BL}$ may prevent ovulation of the oocyte from 
preovulatory follicles, resulting in their premature luteinisation at 9 weeks of age.

Successful ovulation implies meiotic resumption and release of the oocyte, and the structural remodelling and luteinisation of the follicle. These processes are regulated by complex signalling between the somatic cells and the oocyte in response to an LH surge (Park et al. 2004, Shimasaki et al. 2004, Russell \& Robker 2007). Alterations in signalling, as a consequence of modified structure/function of oocyte glycoproteins and their paracrine interactions, could result in premature luteinisation and ovulation would likely be compromised; this we observed in DM ovaries and has been reported in karotypically normal women with POI (Nelson et al. 1994). Previously, we have reported that 9 week DM females are infertile with scarce ovulations (Grasa et al. 2012). In this study, DM ovaries collected after ovulation contain LUFs, suggesting the absence of both $\mathrm{O}$ - and $\mathrm{N}$-glycans results in defects in preovulatory follicles culminating in a failure to ovulate. The exact mechanism by which preovulatory follicles fail to ovulate is unclear. However, evidence that the high circulating $\mathrm{FSH}$ levels in DM females may be inducing luteinisation comes from an in vivo study by van de Lagemaat et al. (2011), who demonstrated oral administration of short-acting FSHR agonist induced luteinisation of preovulatory follicles in rats, guinea pigs and cynomolgus monkeys. It has been suggested that the FSHR agonist mimics the rise of CAMP in GCs observed following the LH surge (Richards et al. 1998) and thus induces a suboptimal ovulation that results in the generation of a LUF. Indeed, it has been established that the actions of FSH are mediated through secondary messengers including cAMP (Robker \& Richards 1998, Sirard et al. 2007) and therefore we speculate that the high circulating FSH levels in DM are responsible for the ovulation failure, resulting in the production of LUFs.

In this study, delayed CL regression in DM ovaries was found to be due to attenuated rates of luteal cell apoptosis, which would explain the high number of CL observed in DM ovaries (Grasa et al. 2012) since ovulation rate is equivalent at this age (Grasa et al. 2012). The fact that luteinised abnormal structures are found in 3 month DM ovaries accompanied by normal progesterone serum levels, despite the lack of ovulations (Williams \& Stanley 2011), would indicate that functional regression is disrupted in these mice and luteal cells from the $\mathrm{CL}$ remain steroidogenically active. Regression of the $\mathrm{CL}$ or luteolysis begins with the loss of ability to produce progesterone followed by the loss of the cells that form the CL (Niswender et al. 2000). CL regression is required for normal reproductive function, which is not the case in the DM (Williams \& Stanley 2011), and therefore it is possible that the abnormally regressing $\mathrm{CL}$ have a role in DM reproductive dysfunction. Furthermore, FSH plays a role in GC proliferation, survival and differentiation (Richards et al. 1995) through the PI3K pathway
(Alam et al. 2004). Targeted disruption of an inhibitor of the PI3K pathway, Pten, in GC resulted in the persistence of $C L$ as a result of the increased lifespan of luteal cells (Fan et al. 2008). Therefore, it is possible that the high FSH levels in DM females mediate activation of the PI3K pathway resulting in the persistence of $\mathrm{CL}$ by extending the lifespan of luteal cells.

In this study, we also determined that despite the infertility, DM females are sexually receptive. This also suggests there is some ovarian steroidogenic activity present in DM females and also challenges the current paradigm that follicle development tightly regulates reproductive cyclicity. It is well known that oestrogen regulates sexual behaviour by acting on the brain (Ogawa et al. 1998, Flanagan-Cato 2000, 2011) and is responsible for the cornification of the vaginal epithelium observed during the oestrous phase. One possible explanation for the reproductive behaviour of DM females despite abnormal follicle development, could be that as the CL produce oestrogen, estradiol serum levels are not modified in these females suggesting that at least some signalling between the hypothalamic-pituitary-gonadal axis remains intact and so regular cycles remain.

In conclusion, we have investigated the aetiology of POI in a mouse model of follicular POI and have revealed multiple defects in follicle development and ovarian function before the presence of the POI phenotype. Although rodent ovarian function and luteal control is different to women, many of our reported findings have already been observed in women suffering from POI. Thus, identifying these follicular modifications have provided insight into the mechanisms driving the development of POI and highlight the opportunity the DM mouse model offers to investigate the pathogenesis of $\mathrm{POI}$ and potentially to develop new fertility treatments.

\section{Declaration of interest}

The authors declare that there is no conflict of interest that could be perceived as prejudicing the impartiality of the research reported.

\section{Funding}

This work was supported by a grant awarded from the Medical Research Council to S A W (G090058). S S is a recipient of a Leverhulme Postgraduate bursary and EPA Cephalosporin Scholarship from Linacre College, University of Oxford. N K, $\mathrm{K} M, \mathrm{~S}$ J, and $\mathrm{P} N$ were partially funded by the NDOG.

\section{Acknowledgements}

We thank Dr Panayiota Ploutarchou for her technical assistance with TUNEL assays and to members of the animal facility for technical assistance with the mice. 


\section{References}

Alam H, Maizels ET, Park Y, Ghaey S, Feiger ZJ, Chandel NS \& HunzickerDunn M 2004 Follicle-stimulating hormone activation of hypoxiainducible factor- 1 by the phosphatidylinositol 3-kinase/AKT/Ras homolog enriched in brain (Rheb)/mammalian target of rapamycin (mTOR) pathway is necessary for induction of select protein markers of follicular differentiation. Journal of Biological Chemistry 279 19431-19440. (doi:10.1074/jbc.M401235200)

Aten RF, Kolodecik TR \& Behrman HR 1995 A cell adhesion receptor antiserum abolishes, whereas laminin and fibronectin glycoprotein components of extracellular matrix promote, luteinization of cultured rat granulosa cells. Endocrinology 136 1753-1758. (doi:10.1210/ en.136.4.1753)

Carambula SF, Matikainen T, Lynch MP, Flavell RA, Goncalves PB, Tilly JL \& Rueda BR 2002 Caspase-3 is a pivotal mediator of apoptosis during regression of the ovarian corpus luteum. Endocrinology 143 1495-1501. (doi:10.1210/endo.143.4.8726)

Christensen AP, Patel SH, Grasa P, Christian HC \& Williams SA 2015 Oocyte glycoproteins regulate the form and function of the follicle basal lamina and theca cells. Developmental Biology 401 287-298. (doi:10.1016/j.ydbio.2014.12.024)

Coulam CB, Adamson SC \& Annegers JF 1986 Incidence of premature ovarian failure. Obstetrics and Gynecology 67 604-606.

Davis JS \& Rueda BR 2002 The corpus luteum: an ovarian structure with maternal instincts and suicidal tendencies. Frontiers in Bioscience 7 d1949-d1978. (doi:10.2741/davis1)

Dixit H, Rao LK, Padmalatha VV, Kanakavalli M, Deenadayal M, Gupta N, Chakrabarty B \& Singh L 2006 Missense mutations in the BMP15 gene are associated with ovarian failure. Human Genetics 119 408-415. (doi:10.1007/s00439-006-0150-0)

Dorrington JH, McKeracher HL, Chan AK \& Gore-Langton RE 1983 Hormonal interactions in the Control of granulosa cell differentiation. Journal of Steroid Biochemistry 19 17-32. (doi:10.1016/S00224731(83)80003-X)

Eppig J 2001 Oocyte Control of ovarian follicular development and function in mammals. Reproduction 122 829-838. (doi:10.1530/rep.0.1220829)

Fan HY, Liu Z, Cahill N \& Richards JS 2008 Targeted disruption of Pten in ovarian granulosa cells enhances ovulation and extends the life span of luteal cells. Molecular Endocrinology 22 2128-2140. (doi:10.1210/ me.2008-0095)

Flanagan-Cato LM 2000 Estrogen-induced remodeling of hypothalamic neural circuitry. Frontiers in Neuroendocrinology 21 309-329. (doi:10.1006/frne.2000.0204)

Flanagan-Cato LM 2011 Sex differences in the neural circuit that mediates female sexual receptivity. Frontiers in Neuroendocrinology 32 124-136. (doi:10.1016/j.yfrne.2011.02.008)

Fujiwara H, Honda T, Ueda M, Nakamura K, Yamada S, Maeda M \& Mori T 1997 Laminin suppresses progesterone production by human luteinizing granulosa cells via interaction with integrin alpha 6 beta 1. Journal of Clinical Endocrinology and Metabolism 82 2122-2128. (doi:10.1210/ jc.82.7.2122)

Grasa P, Kaune H \& Williams SA 2012 Embryos generated from oocytes lacking complex $\mathrm{N}$ - and O-glycans have compromised development and implantation. Reproduction 144 455-465. (doi:10.1530/REP-12-0084)

Grasa P, Ploutarchou P \& Williams SA 2015 Oocytes lacking O-glycans alter follicle development and increase fertility by increasing follicle FSH sensitivity, decreasing apoptosis, and modifying GDF9: BMP15expression. FASEB Journal 29 525-539. (doi:10.1096/fj.14-253757)

Greenwald GS 1972 Of eggs and follicles. American Journal of Anatomy 135 1-3. (doi:10.1002/aja.1001350102)

Hirshfield AN 1991 Development of follicles in the mammalian ovary. International Review of Cytology 124 43-101. (doi:10.1016/s00747696(08)61524-7)

Hirshfield AN 1992 Heterogeneity of cell populations that contribute to the formation of primordial follicles in rats. Biology of Reproduction $\mathbf{4 7}$ 466-472. (doi:10.1095/biolreprod47.3.466)

Hubayter ZR, Popat V, Vanderhoof VH, Ndubizu O, Johnson D, Mao E, Calis KA, Troendle JF \& Nelson LM 2010 A prospective evaluation of antral follicle function in women with $46, \mathrm{XX}$ spontaneous primary ovarian insufficiency. Fertility and Sterility 94 1769-1774. (doi:10.1016/j. fertnstert.2009.10.023)

Irving-Rodgers HF, Hummitzsch K, Murdiyarso LS, Bonner WM, Sado Y, Ninomiya Y, Couchman JR, Sorokin LM \& Rodgers RJ 2010 Dynamics of extracellular matrix in ovarian follicles and corpora lutea of mice. Cell and Tissue Research 339 613-624. (doi:10.1007/s00441-009-0905-8)

Ju T, Brewer K, D'Souza A, Cummings RD \& Canfield WM 2002a Cloning and expression of human core 1 beta1,3-galactosyltransferase. Journal of Biological Chemistry 277 178-186. (doi:10.1074/jbc.M109060200)

Ju T, Cummings RD \& Canfield WM 2002b Purification, characterization, and subunit structure of rat core 1 Beta1,3-galactosyltransferase. Journal of Biological Chemistry 277 169-177. (doi:10.1074/jbc.M109056200)

Laissue P, Christin-Maitre S, Touraine P, Kuttenn F, Ritvos O, Aittomaki K, Bourcigaux N, Jacquesson L, Bouchard P, Frydman R et al. 2006 Mutations and sequence variants in GDF9 and BMP15 in patients with premature ovarian failure. European Journal of Endocrinology $\mathbf{1 5 4}$ 739-744. (doi:10.1530/eje.1.02135)

Massin N, Gougeon A, Meduri G, Thibaud E, Laborde K, Matuchansky C, Constancis E, Vacher-Lavenu MC, Paniel B, Zorn JR et al. 2004 Significance of ovarian histology in the management of patients presenting a premature ovarian failure. Human Reproduction 19 2555-2560. (doi:10.1093/humrep/deh461)

Matzuk MM, Burns KH, Viveiros MM \& Eppig J 2002 Intercellular communication in the mammalian ovary: oocytes carry the conversation. Science 296 2178-2180. (doi:10.1126/science.1071965)

Mehta AE, Matwijiw I, Lyons EA \& Faiman C 1992 Noninvasive diagnosis of resistant ovary syndrome by ultrasonography. Fertility and Sterility $\mathbf{5 7}$ 56-61. (doi:10.1016/S0015-0282(16)54776-1)

Meskhi A \& Seif MW 2006 Premature ovarian failure. Current Opinion in Obstetrics and Gynecology 18 418-426. (doi:10.1097/01. gco.0000233937.36554.d3)

Mork L, Maatouk DM, McMahon JA, Guo JJ, Zhang P, McMahon AP \& Capel B 2012 Temporal differences in granulosa cell specification in the ovary reflect distinct follicle fates in mice. Biology of Reprodution 8637. (doi:10.1095/biolreprod.111.095208)

Nelson LM 2009 Clinical practice. Primary ovarian insufficiency. New England Journal of Medicine 360 606-614. (doi:10.1056/NEJMcp0808697)

Nelson JF, Felicio LS, Randall PK, Sims C \& Finch CE 1982 A longitudinal study of estrous cyclicity in aging C57BL/6J mice: I. Cycle frequency, length and vaginal cytology. Biology of Reproduction 27 327-339. (doi:10.1095/biolreprod27.2.327)

Nelson LM, Anasti JN, Kimzey LM, Defensor RA, Lipetz KJ, White BJ, Shawker TH \& Merino MJ 1994 Development of luteinized graafian follicles in patients with karyotypically normal spontaneous premature ovarian failure. Journal of Clinical Endocrinology and Metabolism 79 1470-1475. (doi:10.1210/jc.79.5.1470)

Niswender GD, Juengel JL, Silva PJ, Rollyson MK \& McIntush EW 2000 Mechanisms controlling the function and life span of the corpus luteum. Physiological Reviews 80 1-29.

Ogawa S, Eng V, Taylor J, Lubahn DB, Korach KS \& Pfaff DW 1998 Roles of estrogen receptor-alpha gene expression in reproduction-related behaviors in female mice. Endocrinology 139 5070-5081. (doi:10.1210/ en.139.12.5070)

Park JY, Su YQ, Ariga M, Law E, Jin SL \& Conti M 2004 EGF-like growth factors as mediators of LH action in the ovulatory follicle. Science $\mathbf{3 0 3}$ 682-684. (doi:10.1126/science.1092463)

Philpott CC, Ringuette MJ \& Dean J 1987 Oocyte-specific expression and developmental regulation of ZP3, the sperm receptor of the mouse zona pellucida. Developmental Biology 121 568-575. (doi:10.1016/00121606(87)90192-8)

Ploutarchou P, Melo P, Day AJ, Milner CM \& Williams SA 2015 Molecular analysis of the cumulus matrix: insights from mice with O-glycan-deficient oocytes. Reproduction 149 533-543. (doi:10.1530/REP-14-0503)

Richards JS, Fitzpatrick SL, Clemens JW, Morris JK, Alliston T \& Sirois J 1995 Ovarian cell differentiation: a cascade of multiple hormones, cellular signals, and regulated genes. Recent Progress in Hormone Research 50 223-254. (doi:10.1016/b978-0-12-571150-0.50014-7)

Richards JS, Russell DL, Robker RL, Dajee M \& Alliston TN 1998 Molecular mechanisms of ovulation and luteinization. Moleular and Cellular Endocrinology 145 47-54. (doi:10.1016/S0303-7207(98)00168-3) 
Robertson MA, Etchison JR, Robertson JS, Summers DF \& Stanley P 1978 Specific changes in the oligosaccharide moieties of VSV grown in different lectin-resistnat CHO cells. Cell 13 515-526. (doi:10.1016/00928674(78)90325-2)

Robker RL \& Richards JS 1998 Hormone-induced proliferation and differentiation of granulosa cells: a coordinated balance of the cell cycle regulators cyclin D2 and p27Kip1. Molecular Endocrinology 12 924-940. (doi:10.1210/mend.12.7.0138)

Rodgers RJ, van Wezel IL, Irving-Rodgers HF, Lavranos TC, Irvine CM \& Krupa M 1999 Roles of extracellular matrix in follicular development. Journal of Reproduction and Fertility 54 343-352.

Russell DL \& Robker RL 2007 Molecular mechanisms of ovulation: coordination through the cumulus complex. Human Reproduction Update 13 289-312. (doi:10.1093/humupd/dml062)

Schlesinger S, Gottlieb C, Feil P, Gelb N \& Kornfeld S 1975 Growth of enveloped RNA viruses in a line of chinese hamster ovary cells with deficient $\mathrm{N}$-acetylglucosaminyltransferase activity. Journal of Virology $\mathbf{1 7}$ 239-246.

Shelling AN 2010 Premature ovarian failure. Reproduction 140 633-641. (doi:10.1530/REP-09-0567)

Shi S, Williams SA, Seppo A, Kurniawan H, Chen W, Ye Z, Marth JD \& Stanley P 2004 Inactivation of the Mgat1 gene in oocytes impairs oogenesis, but embryos lacking complex and hybrid N-glycans develop and implant. Molecular and Cellular Biology 24 9920-9929. (doi:10.1128/MCB.24.22.9920-9929.2004)

Shimasaki S, Moore RK, Otsuka F \& Erickson GF 2004 The bone morphogenetic protein system in mammalian reproduction. Endocrine Reviews 25 72-101. (doi:10.1210/er.2003-0007)

Sirard MA, Desrosier S \& Assidi M 2007 In vivo and in vitro effects of $\mathrm{FSH}$ on oocyte maturation and developmental competence. Theriogenology 68 (Supplement 1) S71-S76. (doi:10.1016/j. theriogenology.2007.05.053)

Suzuki N, Yoshioka1 N, Takae S, Sugishita Y, Tamura M, Hashimoto S, Morimoto Y \& Kawamura K 2015 Successful fertility preservation following ovarian tissue vitrification in patients with primary ovarian insufficiency. Human Reproduction 30 608-615. (doi:10.1093/humrep/deu353)

van de Lagemaat $R$, van Koppen CJ, Krajnc-Franken MA, Folmer BJ, van Diepen HA, Mulders SM \& Timmers CM 2011 Contraception by induction of luteinized unruptured follicles with short-acting low molecular weight FSH receptor agonists in female animal models. Reproduction 142 893-905. (doi:10.1530/REP-11-0234)

Williams SA \& Stanley P 2008 Mouse fertility is enhanced by oocytespecific loss of core 1-derived O-glycans. FASEB Journal 22 2273-2284. (doi:10.1096/fj.07-101709)

Williams SA \& Stanley P 2009 Oocyte-specific deletion of complex and hybrid $\mathrm{N}$-glycans leads to defects in preovulatory follicle and cumulus mass development. Reproduction 137 321-331. (doi:10.1530/REP-07-0469)

Williams SA \& Stanley P 2011 Premature ovarian failure in mice with oocytes lacking core 1-derived O-glycans and complex N-glycans. Endocrinology 152 1057-1066. (doi:10.1210/en.2010-0917)

Williams SA, Xia L, Cummings RD, McEver RP \& Stanley P 2007 Fertilization in mouse does not require terminal galactose or $\mathrm{N}$-acetylglucosamine on the zona pellucida glycans. Journal of Cell Science 120 1341-1349. (doi:10.1242/jcs.004291)

Young JM \& McNeilly AS 2010 Theca: the forgotten cell of the ovarian follicle. Reproduction 140 489-504. (doi:10.1530/REP-10-0094)

Zheng W, Zhang H, Gorre N, Risal S, Shen Y \& Liu K 2014 Two classes of ovarian primordial follicles exhibit distinct developmental dynamics and physiological functions. Human Molecular Genetics 23 920-928. (doi:10.1093/hmg/ddt486)

Received 22 February 2016

First decision 21 March 2016

Revised manuscript received 28 July 2016

Accepted 31 August 2016 